\title{
BMJ Open Efficiency and scale effect of county public hospitals in Shandong Province, China: a cross-sectional study
}

\author{
Qian Li (D ,,${ }^{1,2}$ Liqi Tian, ${ }^{1}$ Xiaolin Jing, ${ }^{1}$ Xianghua Chen, ${ }^{1}$ Jiangfeng Li, ${ }^{1}$ Huixin Chen $^{2}$
}

To cite: Li Q, Tian L, Jing X, et al. Efficiency and scale effect of county public hospitals in Shandong Province, China: a cross-sectional study. BMJ Open 2020;10:e035703. doi:10.1136/ bmjopen-2019-035703

- Prepublication history and additional material for this paper are available online. To view these files, please visit the journal online (http://dx.doi org/10.1136/bmjopen-2019035703).

Received 12 November 2019 Revised 04 April 2020 Accepted 01 May 2020

Check for updates

(C) Author(s) (or their employer(s)) 2020. Re-use permitted under CC BY-NC. No commercial re-use. See rights and permissions. Published by BMJ.

${ }^{1}$ The Affiliated Hospital of Qingdao University, Qingdao, Shandong Province, China

${ }^{2}$ Department of Social Medicine and Health Management, School of Medicine, Qingdao University, Qingdao, Shandong Province,

China

Correspondence to

Dr Liqi Tian; tlq1738@sina.com

\section{ABSTRACT}

Objective To evaluate the efficiency of county public hospitals in Shandong Province following China's new medical reform and compare the efficiency of hospitals with different bed sizes for improving efficiency.

Design and setting This was a cross-sectional study on the efficiency and size of 68 county public hospitals in China in 2017.

Outcome measures Data envelopment analysis was used to calculate the efficiency scores of hospitals and to analyse the slack values of inefficient hospitals. The actual number of open beds, doctors, nurses and total expenditure were selected as inputs, and the total number of annual visits, discharges and total income were selected as outputs. The Kruskal-Wallis $\mathrm{H}$ test was employed to compare the efficiency of hospitals with different bed sizes. The $\chi^{2}$ test was used to compare the returns to scale (RTS) of hospitals with different bed sizes.

Results Twenty $(29.41 \%)$ hospitals were efficient. There were 27 hospitals with increasing returns to scale, 23 hospitals with constant returns to scale and 18 hospitals with decreasing returns to scale (DRS). The differences in technical efficiency $(p=0.248, p>0.05)$ and pure technical efficiency $(p=0.073, p>0.05)$ were not statistically significant. However, the differences in scale efficiency $(p=0.047, p<0.05)$ and RTS $(p<0.001)$ were statistically significant. Hospitals with DRS began to appear at 885 beds. All sample hospitals with more than 1100 beds were already saturated and some hospitals even had a negative scale effect.

Conclusions The government and hospital managers should strictly control the bed size in hospitals and make hospitals resume operating in the interests of public welfare. Interventions that rationally allocate health resources and improve the efficiency of medical workers are conducive to solving redundant inputs and insufficient outputs.

\section{INTRODUCTION}

The unreasonable allocation and utilisation of resources have seriously affected the production efficiency of health services. ${ }^{1}$ Pursuing efficiency is of vital importance to policy-makers and hospital managers. ${ }^{2}$ Evaluating hospital efficiency can help hospital policy-makers improve inefficiencies with rational policies and help managers to know
Strengths and limitations of this study

The data envelopment analysis (DEA) accommodated multiple inputs and multiple outputs, which is in line with the characteristics of hospitals.

- The DEA did not need to use a common denominator, ensuring the diversity of indicators.

- This study identified the extent and source of hospital inefficiencies to help hospitals take remedial measures.

- The results produced by the DEA were sensitive to measurement errors and may underestimate or overestimate the efficiency scores.

- Due to the objective limitations of the data, the study included hospitals only in eastern China.

whether medical resources are optimally allocated and fully used.

The focus of medical reform in China has been on hospital efficiency and quality. Prior studies held that the efficiency of hospitals needed to be further improved and there were some problems such as the inefficient allocation of resources and the blind expansion of scale. ${ }^{34}$ In 2016, the National Health Commission issued 'Guidelines for Medical Institution Planning (2016-2020)', which required hospitals to strictly control the bed size. Unfortunately, there has been no significant effect. In fact, in most hospitals, the number of beds is still on the rise. The price of medical services in China is regulated by the government, and the zero-price gap policy for drugs and consumables has severely curtailed the sources of hospital revenue. Although it is a public hospital, government investment is insufficient to meet the needs of hospital development. The expansion of scale can attract more health resources and financial investment for hospitals, and it can also reduce the unit cost. Therefore, the benefits of hospital expansion in China are compelling. Of course, the reasons for expansion do not rule out the increase in medical demand. 


\begin{tabular}{lll}
\hline Table 1 & Definition of the inputs and outputs & \\
Category & Variable & Definition \\
\hline Inputs & Actual number of open beds & The number of beds actually opened at the end of the year. \\
& Number of doctors & The number of practising (assistant) physicians. \\
& Number of nurses & The number of qualified nurse practitioners. \\
& Total expenditure & The expenses incurred by the hospital at the end of the year. \\
Outputs & Total number of annual visits & The number of visits, counted by the number of registrations. \\
& Number of discharges & The number of all discharged patients after hospitalisation. \\
& Total income & The total income earned by the hospital at the end of the year.
\end{tabular}

Unexpectedly, the number of beds in the largest public hospital in China has reached 10000 beds. Is it the case that the more hospital beds there are, the better the hospital's efficiency? Most studies on scale efficiency (SE) have focused on analysing the appropriate use of resources ${ }^{56}$ and estimating the optimal size of hospitals. ${ }^{7-9}$ Novosadova and Dlouhy ${ }^{10}$ compared the efficiency of large and small acute hospitals and gave scores in terms of technical efficiency (TE) and SE. It turned out that smaller hospitals tended to be more efficient than larger ones. Fidler et $a l^{11}$ examined the size effect of reorganised hospitals in Austria and Estonia. Policy-makers believed that the combined large hospitals can reduce average costs and improve clinical outcomes. In contrast, employees argued that the merger neither generated economies of scale nor significantly improved quality. In short, regardless of whether hospitals are in China or elsewhere, conducting studies on hospital efficiency and scale economies is crucial to solve the optimal production size and to achieve the fair allocation of resources. ${ }^{12}$

General hospitals are pioneers in the reform of county public hospitals and are also the primary carrier for the government to provide basic medical services to residents living in counties. Shandong Province, located in eastern China, is one of the major coastal provinces. It is also a populous province. At the end of 2017, the total residential population reached more than 100 million. Shandong Province took the lead in starting a comprehensive reform of county public hospitals, which played an exemplary role for the country as a whole. Therefore, taking county public general hospitals in Shandong Province as a sample for evaluating the efficiency and exploring scale effect of county public hospitals is representative. We anticipate that this study will provide a reference for other regions in regard to efficiency evaluation and scale development.

\section{METHODS}

\section{Sample and variable selection}

The data set was collected from the health statistics information reporting system of the Hospital Management Research Institute of Qingdao University and was provided by 71 county public hospitals from March to June 2018. First, DEA premised on the selection of similar decision-making units (DMUs), so the sample was composed of the county public general hospitals. Second, all no variables in the sample hospitals should include missing or abnormal values. Third, this study selected counties with one and only one general hospital. Two hospitals were removed for missing data. Another hospital was removed because the district it belonged to was merged. As a result, 68 hospitals were eventually identified for research under the above-mentioned requirements.

The study selected seven input and output variables that fit the characteristics of hospital efficiency. The actual number of open beds, the number of doctors, the number of nurses and total expenditure were used as inputs, to represent material, human and financial resources. The total number of annual visits, the number of discharges and total income were used as outputs to represent the quantity, quality and benefits of medical services. The variables were determined under the guidance of previous empirical studies. ${ }^{13-17}$ The calculation process was implemented using DEAP V.2.1 software. The specific indicators are explained in table 1 .

\section{Efficiency evaluation methods}

Currently, the evaluation of hospital efficiency focuses on the use of economic models. ${ }^{18} 19$ Stochastic frontier analysis (SFA) and the technique for order preference by similarity to an ideal solution (TOPSIS) are also commonly used in efficiency evaluation. ${ }^{20}{ }^{21}$ SFA is limited to evaluating the objects of multiple inputs and single output. Although absolute efficiency can be measured, the ability to distinguish allocation efficiency from TE is weak. ${ }^{6}$ With the TOPSIS method, the weight of the indexes is subjective, which may affect the accuracy of the results. ${ }^{21}$ International studies have shown that data envelopment analysis (DEA) is an important tool in evaluating hospital efficiency. ${ }^{22-24}$ DEA is a mature and advanced non-parametric method that compensates for the shortcomings of the above-mentioned methods. It can solve problems with multiple inputs and multiple outputs. Not only can efficiency be evaluated and ranked, but the source of inefficient DMUs and the extent of improvement can also be further tracked. ${ }^{13} 19$ 
Table 2 Descriptive statistics of inputs and outputs

\begin{tabular}{|c|c|c|c|c|}
\hline Indicators & Minimum & Maximum & Average & SD \\
\hline \multicolumn{5}{|l|}{ Inputs } \\
\hline Actual number of open beds & 185.0 & 2220.0 & 991.0 & 373.6 \\
\hline Number of nurses & 149.0 & 971.0 & 529.3 & 191.5 \\
\hline Total expenditure (10 000¥) & 8184.0 & 90030.0 & 41587.8 & 17910.3 \\
\hline Total number of annual visits & 87116.0 & 1511751.0 & 527816.1 & 257916.2 \\
\hline Number of discharges & 8689.0 & 99565.0 & 43127.6 & 17099.7 \\
\hline Total income (10 000¥) & 8133.3 & 91991.0 & 42958.6 & 18356.4 \\
\hline
\end{tabular}

\section{Data envelopment analysis}

DEA is an evaluation method that was first proposed by the famous American operations researcher A. Charnes and scholar W.W. Cooper ${ }^{22}$ in 1978, based on the concept and connotation of relative efficiency. ${ }^{26}$ CCR and BCC are the most commonly used models. ${ }^{2}$ In this paper, a two-stage DEA was used to conduct research using the CCR (Charnes, Cooper and Rhodes) and BCC (Banker, Charnes and Cooper) models of the outputoriented model. The output-oriented model involves how to increase or maximise output without changing the proportion of input. ${ }^{1722}$ Based on the assumption of constant returns to scale (CRS), Charnes et al extended and developed the CCR model, which is mainly used to measure the TE score of DMUs. ${ }^{27}$ A score equal to 1 indicates that the DMU is efficient. A score of $<1$ indicates that the DMU is inefficient.

$$
\begin{gathered}
\left(D_{\mathrm{CCR}}\right)\left\{\begin{array}{c}
\max \varphi \\
\sum_{j=1}^{n} x_{j} \lambda_{j} \leq x_{0} \\
\sum_{j=1}^{n} y_{j} \lambda_{j} \geq \varphi y 0 \\
\lambda j \geq 0, j=1,2, \cdots, n
\end{array}\right. \\
x_{j}=\left(x_{1 j}, x_{2 i}, \cdots, x_{m i}\right)^{T}>0, y_{j}=\left(y_{1 i}, y_{2 i}, \cdots, y_{s j}\right)^{T}>0, \\
x_{0}=x_{j 0}, y_{0}=y_{j 0}, 1 \leq j_{0} \leq n
\end{gathered}
$$

The scholars then developed the BCC model based on the variable return to scale to separate pure technical efficiency (PTE) from SE. ${ }^{28}$ The BCC model mainly measures the PTE and SE of the DMU. ${ }^{29}$ The BCC model is an extension of the CCR model.

$$
\left(D_{\mathrm{BCC}}\right)\left\{\begin{array}{c}
\min \varphi \\
\sum_{j=1}^{n} x_{j} \lambda_{j} \leq x_{0} \\
\sum_{j=1}^{n} y_{j} \lambda_{j} \geq \varphi y_{0} \\
\sum_{j=1}^{n} \lambda_{j}=1 \\
\lambda_{j} \geq 0, j=1,2, \cdots n
\end{array}\right.
$$

$$
\begin{gathered}
x_{j}=\left(x_{1 j}, x_{2 j}, \cdots, x_{m j}\right)^{T}>0, y_{j}=\left(y_{1 j}, y_{2 i}, \cdots, y_{s j}\right)^{T}>0 \\
x_{0}=x_{j 0}, y_{0}=y_{j 0}, 1 \leq j_{0} \leq n
\end{gathered}
$$

\section{Statistical methods}

This study defined the size of hospitals based on the actual number of open beds. The sample hospitals were divided into four groups: 500 beds and below, 501-1000 beds, 1001-1500 beds and 1501 beds and above. The Kruskal-Wallis H non-parametric test was used to compare the efficiency of hospitals with different bed sizes. Efficiency included TE, PTE and SE. The $\chi^{2}$ test was used to compare the differences in the returns to scale (RTS) of hospitals with different bed sizes. Statistical analysis was performed using SPSS V.25.0.

\section{Patient and public involvement}

Patients and/or the public were not involved in the design, or conduct, or reporting, or dissemination plans of this research.

\section{RESULTS}

Description of the inputs and outputs

Table 2 is a descriptive summary of the inputs and outputs of the 68 sample hospitals. The data indicated that the average number of open beds per hospital was 991.0 in 2017. The average number of doctors and nurses per hospital was 352.7 and 529.3, respectively. With an average of 527816.1 visits per hospital per year, the efficiency of the hospitals is commendable.

\section{Hospital efficiency scores from the DEA}

Table 3 shows the distribution of the efficiency scores for the sample hospitals. Only $20(29.41 \%)$ hospitals were $100 \%$ efficient in TE and $48(70.59 \%)$ hospitals were inefficient. The PTE of $26(38.24 \%)$ hospitals was efficient, whereas the remaining $42(61.76 \%)$ were inefficient. All hospitals had SE scores above 0.900 , but only 23 $(33.82 \%)$ were fully efficient. The efficiency score of all sample hospitals are shown in the online supplementary appendix 1 . 
Table 3 Distribution of the efficiency scores for the sample hospitals

\begin{tabular}{|c|c|c|c|c|}
\hline Scoring range & 1.000 & $0.999-0.900$ & $0.899-0.800$ & $0.799-0.700$ \\
\hline Technical efficiency & $20(29.41 \%)$ & 32 (47.06\%) & $15(22.06 \%)$ & $1(1.47 \%)$ \\
\hline Scale efficiency & $23(33.82 \%)$ & $45(66.18 \%)$ & $0(0.00 \%)$ & $0(0.00 \%)$ \\
\hline
\end{tabular}

\section{Slack value of the inputs and outputs of inefficient hospitals}

This study analysed the slack values of 48 inefficient hospitals. In other words, the differences between the actual value and the ideal value of the variables were calculated. Taking hospital H16 as an example, the actual number of doctors was 38.8 more than the ideal number. As shown in table 4, hospital H16 needs to increase the total number of visits by $15 \%$, the number of discharges by $6 \%$ and total income by $6 \%$ to make full use of its current resources.

\section{Differences in TE, PTE and SE among hospitals with different bed sizes}

There were no significant differences in TE $(p=0.248$, $\mathrm{p}>0.05)$ and PTE $(p=0.073, p>0.05)$ among the four comparison groups. However, the difference in SE was statistically significant $(\mathrm{p}=0.047, \mathrm{p}<0.05)$ (see table 5 for details).

\section{Differences in RTS among hospitals with different bed sizes}

The findings in table 6 suggested that the difference in the RTS of hospitals with different bed sizes was significant $(p<0.001)$. Twenty-three hospitals with the SE score equal to 1 were CRS. This means that these hospitals not only have the optimal bed size but also have the lowest operation costs, additionally, their inputs and outputs were in balance. The inefficient hospitals were divided into two categories: increasing returns to scale (IRS) and decreasing returns to scale (DRS). The 27 hospitals with IRS had insufficient inputs and needed to expand their scale to achieve better efficiency. The 18 hospitals with DRS had redundant inputs and needed to scale down and optimise their allocation of resources.

A scatter plot was produced to highlight the relationship between bed size, SE and RTS. As depicted in figure 1 , with the increase in the number of hospital beds, the SE of hospitals approximately first increased and then decreased. It was obvious that only one hospital was efficient in the $\geq 1501$ beds group, and the remaining four hospitals were not only inefficient but also had a low SE score.

In addition, hospitals with DRS began to appear at 885 beds. A large number of hospitals in the 1001-1500 beds and $\geq 1501$ beds groups were already in DRS. Of the 11 hospitals with more than 1300 beds, 9 (81.8\%) were DRS. When the bed size exceeded 1100 beds, there were no longer hospitals with IRS. All sample hospitals with more than 1100 beds were already saturated and some hospitals even had a negative scale effect.

\section{DISCUSSION}

An increasing number of countries have been using DEA to evaluate hospital efficiency. ${ }^{2} 141830$ The findings indicated that 48 sample hospitals were inefficient. That was, more than $70 \%$ of hospitals had problems of excessive inputs or insufficient outputs, which was consistent with the results of many experts. ${ }^{131} 32$ Cheng et $a l^{31}$ suggested that only $8.8 \%$ of the 114 county hospitals in Henan Province, China, were defined as technically efficient and proposed that the efficiency needed to be improved. Our study found that the outputs of inefficient hospitals had higher slack values, largely because of underused resources. In the research on the equity and efficiency of health resource allocation in mainland China, Zhang et $a l^{33}$ pointed out that many provinces in China had problems of idle and underused health resources. This may be due to the inefficient use of resources by medical staff. It may also be because county hospitals are limited by their own service capabilities, resulting in a loss of patients, which makes resources idle and difficult to use efficiently in turn.

The blind expansion of bed size is a common problem in Chinese hospitals. ${ }^{34}$ In theory, due to economies of scale, more beds should result in higher efficiency scores. However, the results did not prove that the scale

Table 4 The slack value of the inputs and outputs of hospital H16

\begin{tabular}{|c|c|c|c|c|c|c|c|c|}
\hline \multirow[b]{2}{*}{ DMU } & \multirow[b]{2}{*}{ Related indicators } & \multicolumn{4}{|c|}{ Inputs } & \multicolumn{3}{|c|}{ Outputs } \\
\hline & & Beds & Doctors & Nurses & Expenditure & Visits & Discharges & Income \\
\hline \multirow[t]{3}{*}{$\mathrm{H} 16$} & Actual value & 717.0 & 300.0 & 344.0 & 27508.0 & 418402.0 & 35536.0 & 28743.0 \\
\hline & Slack value & 0.00 & 38.8 & 0.00 & 0.00 & -61391.2 & -2264.8 & -1831.8 \\
\hline & Change ratio & $0 \%$ & $13 \%$ & $0 \%$ & $0 \%$ & $-15 \%$ & $-6 \%$ & $-6 \%$ \\
\hline
\end{tabular}

DMU, decision-making unit. 


\begin{tabular}{|c|c|c|c|c|}
\hline Efficiency & Bed size & $\bar{X}_{ \pm \mathbf{S}}$ & $\chi^{2}$ value & P value \\
\hline \multirow{4}{*}{$\begin{array}{l}\text { Technical } \\
\text { efficiency }\end{array}$} & $\leq 500$ beds & $0.965 \pm 0.049$ & \multirow[t]{4}{*}{4.131} & \multirow[t]{4}{*}{0.248} \\
\hline & $501-1000$ beds & $0.927 \pm 0.064$ & & \\
\hline & $1001-1500$ beds & $0.957 \pm 0.045$ & & \\
\hline & $\geq 1501$ beds & $0.930 \pm 0.046$ & & \\
\hline \multirow{4}{*}{$\begin{array}{l}\text { Pure } \\
\text { technical } \\
\text { efficiency }\end{array}$} & $\leq 500$ beds & $0.983 \pm 0.031$ & \multirow[t]{4}{*}{6.954} & \multirow[t]{4}{*}{0.073} \\
\hline & $501-1000$ beds & $0.934 \pm 0.060$ & & \\
\hline & $1001-1500$ beds & $0.967 \pm 0.041$ & & \\
\hline & $\geq 1501$ beds & $0.979 \pm 0.037$ & & \\
\hline \multirow{4}{*}{$\begin{array}{l}\text { Scale } \\
\text { efficiency }\end{array}$} & $\leq 500$ beds & $0.989 \pm 0.022$ & \multirow[t]{4}{*}{10.321} & \multirow[t]{4}{*}{0.047} \\
\hline & $501-1000$ beds & $0.992 \pm 0.011$ & & \\
\hline & $1001-1500$ beds & $0.989 \pm 0.013$ & & \\
\hline & $\geq 1501$ beds & $0.951 \pm 0.032$ & & \\
\hline
\end{tabular}

difference in hospital TE was significant. This may be because the effect of bed size on TE is not obvious or the difference depends on the combined effect of size and other factors. As a public welfare undertaking led by the government, the development of hospitals cannot be separated from the support of the government. In recent years, the government has reduced the supply of resources to hospitals with DRS by imposing reasonable controls on hospital construction and the purchase of large equipment. ${ }^{35}$ Asmild et $a \hat{l}^{36}$ used DEA to study the optimal size of hospitals, especially the relationship between efficiency and size, and indicated that different hospitals had different efficiencies that depended on location, the population served and the policies, which provincial governments wish to implement.

The difference in PTE was not significant. It can be speculated that the siphon effect of scale on medical technology and equipment had been alleviated. In the future, regardless of the size of the hospital, medical technology and equipment will gradually achieve fairness and homogeneity. This will be a good vision for future hospital development. The hospitals scored higher on PTE, with an average score of 0.951. Shandong Province and other areas of China have given strong support and attention to the investment and renewal of medical equipment, the

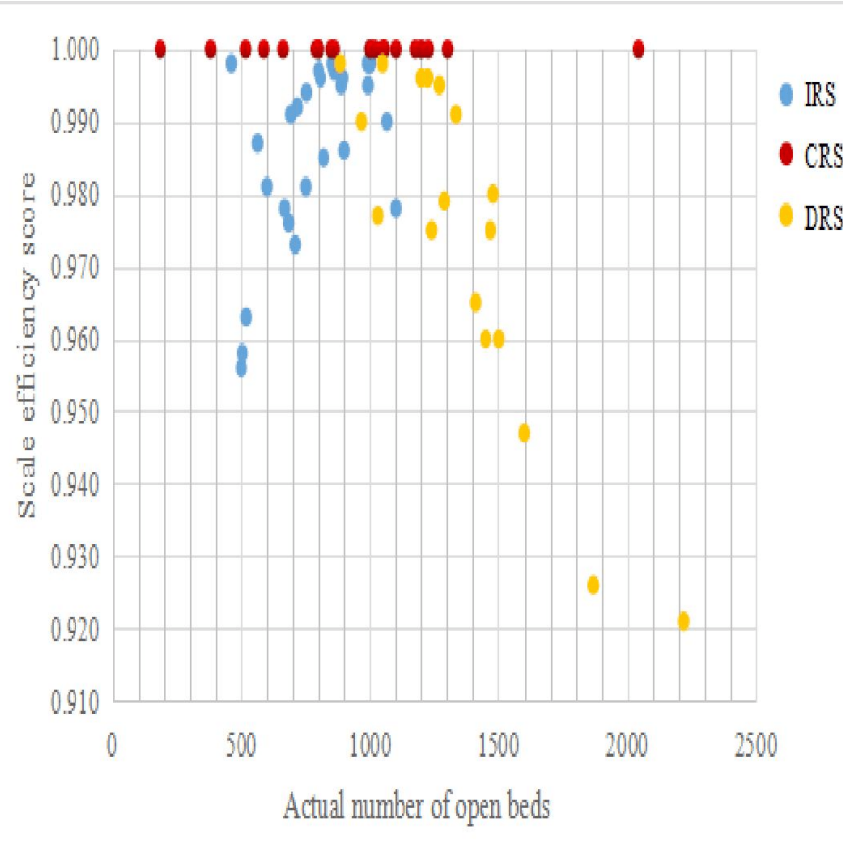

Figure 1 Scatter plot of the relationship between bed size and scale efficiency and returns to scale. CRS, constant returns to scale; DRS, decreasing returns to scale; IRS, increasing returns to scale.

strengthening of hospital information systems, ${ }^{37}$ and the connection of internet hospitals. Excluding the impact of scale factors, hospitals have produced better improvements in efficiency through pure technology.

This study found that the bed size will affect the SE and RTS of hospitals. Below a critical range, an increase in the number of beds can lead to an increase in efficiency, but beyond the threshold, the increase will result in a decrease in efficiency. The findings indicated that hospitals with DRS began to appear at 885 beds. A large number of hospitals in the 1001-1500 beds and $\geq 1501$ beds groups were already in DRS. However, Dong ${ }^{38}$ stated that the vast majority of county hospitals in Hubei Province had more than 335 beds and were generally in a state of DRS. The results of Dong's study and our study were quite different. Over time, the difference may be related to different factors such as the population base of different provinces and the release of medical service

Table 6 Statistical analysis results of the returns to scale of hospitals with different bed sizes

\begin{tabular}{|c|c|c|c|c|c|c|}
\hline \multirow[b]{2}{*}{ Bed size } & \multicolumn{6}{|c|}{ Returns to scale } \\
\hline & IRS & CRS & DRS & Total & $\chi^{2}$ value & $P$ value \\
\hline$\leq 500$ beds & $2(50 \%)$ & $2(50 \%)$ & $0(0 \%)$ & $4(100 \%)$ & 32.023 & $<0.001$ \\
\hline $501-1000$ beds & $23(63.89 \%)$ & 11 (30.56\%) & 2 (5.56\%) & 36 (100\%) & & \\
\hline $1001-1500$ beds & 2 (8.70\%) & $9(39.13 \%)$ & 12 (52.17\%) & $23(100 \%)$ & & \\
\hline$\geq 1501$ beds & $0(0 \%)$ & $1(20 \%)$ & $4(80 \%)$ & $5(100 \%)$ & & \\
\hline Total & 27 & 23 & 18 & 68 & & \\
\hline
\end{tabular}

CRS, constant returns to scale; DRS, decreasing returns to scale; IRS, increasing returns to scale. 
demand due to the expansion of China's medical insurance coverage.

Internationally, several articles focused on evaluating the benefits of a hospital scale in business and economics journals showed that the IRS appeared in hospitals with 300 and 600 beds. $^{39}{ }^{40}$ Banker $^{41}$ observed that the IRS could be exploited up to a capacity of approximately 200 beds. Our study concluded that IRS should be controlled below 1100 beds. The scale effect of all sample hospitals with more than 1100 beds was already saturated and some hospitals even had a negative scale effect. Research undertaken in the USA and the UK indicated that diseconomies of scale can be expected to occur below approximately 200 beds and above 600 beds. ${ }^{12}{ }^{42}$ Weaver and Deolalikar ${ }^{9}$ in a research, which is about the scale economies of 654 Vietnamese public hospitals, concluded that economies of scale depend on the type of hospital, as well as the number of beds and outputs. Specifically, when the average number of beds was 516, the Vietnamese Central General Hospitals were in CRS. China is a country with a large population and its demand for medical services is higher than that of other countries. The health sector has been implementing a hierarchical diagnosis and treatment model and striving to make the county hospital visit rate of $90 \%$ by 2020 . The interval of beds for IRS in county public hospitals may be broader than that in other countries.

\section{Limitations}

This study evaluated the efficiency of county public hospitals in Shandong Province following the new medical reform and explored the influence of scale on hospital efficiency. It provided a reference for the government and hospitals to reasonably control bed size and it offered a warning to hospitals with regard to blindly expanding. However, the study has several limitations. First, the sample hospitals were selected from Shandong Province in eastern China, whereas hospitals located in central and western areas were excluded. Second, the data in this study covered only 2017 and cannot form panel data, leading to a lack of longitudinal analysis and comparison. Bias adjustments of efficiency scores were not carried out due to the limitation of the DEA approach. We will continue to track the efficiency of county public hospitals in Shandong Province in the next study.

\section{CONCLUSIONS}

This study evaluated and compared the efficiency of 68 county public hospitals in Shandong Province using DEA. These hospitals had higher efficiency scores, but most hospitals had problems of an unreasonable allocation and inadequate utilisation of health resources. Hospitals should mobilise the enthusiasm of medical staff and continuously improve human efficiency. The synergy between human efficiency and PTE will lead to higher efficiency in hospitals.
This study further demonstrated that the blind expansion of bed size did not lead to greater hospital efficiency. County public hospitals should avoid blindly expanding their scale and should take various effective measures to improve their efficiency. County public hospitals, as the main providers of services to county residents, should accurately locate the service contents based on the functions of hospitals, the types of residents' medical needs and the structure of the population they serve. We hope that this study will provide a reference for other regions to evaluate efficiency and control scale.

Acknowledgements The authors would like to thank 71 county public hospitals for their cooperation and providing the true hospital data. They are very pleased with all the staff of the Hospital Management Research Institute of Qingdao University. The staff are very enthusiastic about the aggregation and cleaning of the data of 71 hospitals, so that the authors have an intuitive understanding of the data. Also, the authors want to thank to XJ for giving a lot of guidance on the writing of the thesis and the correction of the grammar.

Contributors LT and JL: contributed to the conceptualisation and design of the research. XC and HC: spared no effort to collect and standardise data. QL and XC: contributed to the analysis and interpretation of the data and provided statistical analysis support. $\mathrm{XJ}$ : gave guidance on the writing of the article. QL: drafted the article. All authors critically revised the manuscript and eventually approved the version to be released.

Funding The authors have not declared a specific grant for this research from any funding agency in the public, commercial or not-for-profit sectors.

Competing interests None declared.

Patient consent for publication Not required.

Ethics approval Ethical approval was gained from the Ethics Committee of the Affiliated Hospital of Qingdao University.

Provenance and peer review Not commissioned; externally peer reviewed.

Data availability statement Data may be obtained from a third party and are not publicly available. The authors will not share the data for this work. The data for this study were obtained by applying to the Institute of Hospital Management of Qingdao University and involved private information such as hospital financial data.

Open access This is an open access article distributed in accordance with the Creative Commons Attribution Non Commercial (CC BY-NC 4.0) license, which permits others to distribute, remix, adapt, build upon this work non-commercially, and license their derivative works on different terms, provided the original work is properly cited, appropriate credit is given, any changes made indicated, and the use is non-commercial. See: http://creativecommons.org/licenses/by-nc/4.0/.

\section{ORCID iD}

Qian Li http://orcid.org/0000-0003-4365-1359

\section{REFERENCES}

1 Sun J, Luo H. Evaluation on equality and efficiency of health resources allocation and health services utilization in China. Int $J$ Equity Health 2017;16:127.

2 Jia T, Yuan H. The application of DEA (data envelopment analysis) window analysis in the assessment of influence on operational efficiencies after the establishment of branched hospitals. BMC Health Serv Res 2017;17:265.

3 Feng JH. Study on the change of operation efficiency of County public hospitals in Chenzhou City. University Of Nanhua, 2017.

4 JM L, Yao JW, LU J, et al. Analysis of medical service efficiency of county-level public hospitals in Gansu province based on DEA model. Health Soft Sci 2019;33:61-5.

5 Kirigia JM, Emrouznejad A, Cassoma B, et al. A performance assessment method for hospitals: the case of municipal hospitals in Angola. J Med Syst 2008;32:509-19.

6 Varabyova Y, Schreyögg J. International comparisons of the technical efficiency of the hospital sector: panel data analysis of OECD countries using parametric and non-parametric approaches. Health Policy 2013;112:70-9. 
7 Azevedo H, Mateus C. Cost effects of hospital mergers in Portugal. Eur J Health Econ 2014;15:999-1010.

8 Kristensen T, Bogetoft P, Pedersen KM. Potential gains from hospital mergers in Denmark. Health Care Manag Sci 2010;13:334-45.

9 Weaver M, Deolalikar A. Economies of scale and scope in Vietnamese hospitals. Soc Sci Med 2004;59:199-208.

10 Novosadova I, Dlouhy M. Evaluation of technical efficiency of acute hospitals and its relation to wages of health personnel. Ekon Cas 2007;55:783-92.

11 Fidler AH, Haslinger RR, Hofmarcher MM, et al. Incorporation of public hospitals: a "silver bullet" against overcapacity, manageria bottlenecks and resource constraints? Case studies from Austria and Estonia. Health Policy 2007:81:328-38.

12 Giancotti M, Guglielmo A, Mauro M. Efficiency and optimal size of hospitals: results of a systematic search. PLoS One 2017;12:e0174533.

13 Sultan WIM, Crispim J. Measuring the efficiency of palestinian public hospitals during 2010-2015: an application of a two-stage DEA method. BMC Health Serv Res 2018;18:381.

14 Du J, Wang J, Chen Y, et al. Incorporating health outcomes in Pennsylvania hospital efficiency: an additive super-efficiency DEA approach. Ann Oper Res 2014;221:161-72.

15 Kjekshus L, Hagen T. Do hospital mergers increase hospital efficiency? Evidence from a national health service country. $J$ Health Serv Res Policy 2007;12:230-5.

16 Afonso A, Fernandes S. Assessing hospital efficiency: nonparametric evidence for Portugal. SSRN J 2008.

17 Li H, Dong S, Liu T. Relative efficiency and productivity: a preliminary exploration of public hospitals in Beijing, China. BMC Health Serv Res 2014;14:158.

18 Osei D, d'Almeida S, George MO, et al. Technical efficiency of public district hospitals and health centres in Ghana: a pilot study. Cost Eff Resour Alloc 2005;3:9.

19 Marschall P, Flessa S. Efficiency of primary care in rural Burkina Faso. A two-stage DEA analysis. Health Econ Rev 2011;1:5.

20 Goudarzi R, Pourreza A, Shokoohi M, et al. Technical efficiency of teaching hospitals in Iran: the use of stochastic frontier analysis, 1999-2011. Int J Health Policy Manag 2014;3:91-7.

21 Lei RJ, SW L, ZH J. Comparative study of TOPSIS and Rsr in evaluation of hospital bed utilization efficiency. Chin health Stat 2019;36:430-2.

22 Marschall P, Flessa S. Assessing the efficiency of rural health centres in Burkina Faso: an application of data envelopment analysis. $J$ Public Health 2009;17:87-95.

23 Kirigia JM, Sambo LG, Renner A, et al. Technical efficiency of primary health units in Kailahun and Kenema districts of Sierra Leone. Int Arch Med 2011;4:15.

24 Ichoku HE, Fonta WM, Onwujekwe OE, et al. Evaluating the technical efficiency of hospitals in southeastern Nigeria. Eur J Bus Manag $2011 ; 3: 24-37$
25 Ferreira C, Marques RC, Nicola P. On evaluating health centers groups in Lisbon and Tagus Valley: efficiency, equity and quality. BMC Health Serv Res 2013;13:529.

26 Farrell MJ. The measurement of productive efficiency. J R Stat Soc Ser A 1957;120:253-90.

27 Charnes A, Clark CT, Cooper WW, et al. A developmental study of data envelopment analysis in measuring the efficiency of maintenance units in the U.S. air forces. Ann Oper Res 1984;2:95-112.

28 Jacobs R. Alternative methods to examine hospital efficiency: data envelopment analysis and stochastic frontier analysis. Health Care Manag Sci 2001;4:103-15.

29 Banker RD, Charnes A, Cooper WW. Some models for estimating technical and scale Inefficiencies in data envelopment analysis. Manage Sci 1984;30:1078-92.

30 Serván-Mori E, Chivardi C, Mendoza Miguel Ángel, et al. A longitudinal assessment of technical efficiency in the outpatient production of maternal health services in México. Health Policy Plan 2018;33:888-97.

31 Cheng Z, Tao H, Cai M, et al. Technical efficiency and productivity of Chinese county hospitals: an exploratory study in Henan province, China. BMJ Open 2015;5:e007267.

32 Wang X, Luo H, Qin X, et al. Evaluation of performance and impacts of maternal and child health hospital services using data envelopment analysis in Guangxi Zhuang autonomous region, China: a comparison study among poverty and non-poverty county level hospitals. Int J Equity Health 2016;15:131.

33 Zhang $\mathrm{Y}$, Wang Q, Jiang $\mathrm{T}$, et al. Equity and efficiency of primary health care resource allocation in mainland China. Int J Equity Health 2018;17:140.

34 Zhang T. 'Finding reasons' and 'suggestions' for public hospital expansion. , 2017: 15, 64-7.

35 Zhang RH, Liu L, WH L, et al. Evaluation of medical and health service efficiency in 31 provinces and municipalities in China based on data envelopment analysis. Chin Health Econ 2011;30:69-72.

36 Asmild M, Hollingsworth B, Birch S. The scale of hospital production in different settings: one size does not fit all. J Prod Anal 2013;40:197-206.

37 Zhou WT, Li F, Jin CL, et al. Analysis of operational efficiency of health system in districts and counties of Shanghai. Chin Health Stat 2017;34:445-7.

38 Dong SP. Study on the efficiency of scale economy and its influencing factors in county-level general hospitals. Huazhong University of Science and Technology, 2010.

39 Lothgren M, Tambour M. Testing scale efficiency in DEA models: a bootstrapping approach. Appl Econ 1999;31:1231-7.

40 Wilson PW, Carey K. Nonparametric analysis of returns to scale in the US Hospital industry. J Appl Econ 2004;19:505-24.

41 Banker RD. Estimating most productive scale size using data envelopment analysis. Eur J Oper Res 1984:17:35-44.

42 Roh C-Y, Jae Moon M, Jung C. Measuring performance of U.S. nonprofit hospitals. Public Perform Manag Rev 2010;34:22-37. 